\title{
Genes involved in ethylene and gibberellins metabolism are required for endosperm-limited germination of Sisymbrium officinale $\mathbf{L}$. seeds
}

\author{
Germination in Sisymbrium officinale $\mathbf{L}$. seeds
}

Raquel Iglesias-Fernández · Angel J. Matilla

\begin{abstract}
Alustract The rupture of the seed coat and that of the endosperm were found to be two sequential events in the germination of Sisymbrium officinale $\mathbf{L}$. seeds, and radicle protrusion did not occur exactly in the micropylar area but in the neighboring zone. The germination patterns were similar both in the presence of gibberellins $\left(\mathrm{GA}_{4+7}\right)$ and in presence of ethrel. The analysis of genes involved in GAs synthesis and breakdown demonstrated that (1) SoGA2ox6 expression peaked just prior to radicle protrusion $(20-22 \mathrm{~h})$, while SoGA3ox2 and SoGA20ox2 expression was high at early imbibition $(6 \mathrm{~h})$ diminishing sharply thereatter; (2) the accumulation of $S_{0}$ GA200x2 transcript was strongly inhibited by paclobutrazol (PB) as well as by inhibitors of ET synthesis and signaling (IESS) early after imbibition $(6 \mathrm{~h})$, while $S \circ G A 3 \circ \times 2$ and $S O G A 20 x 6$ expression was slowly depressed as germination progressed; (3) ethrel and $\mathrm{GA}_{4+7}$ positively or negatively affected expression of $S O G A 30 \times 2$, SoGA200x2, and SoGA20x6, depending on the germination period studied. Regarding genes involved in ET synthesis, our results showed that SOACS7 was expressed, just prior to radicle emergence while SoACO2 expression slowly increased as germination progressed. Both genes were strongly inhibited by PB but were almost unaffected by externally added ethrel or $\mathrm{GA}_{4+7}$. These results suggest that GAs are more important than ET during the early stages of imbibition, while ET is more
\end{abstract}

important at the late phases of germination of S. officinale L. seeds.

Keywords ACC-and GAs-oxidases - Endospermic seed . Ethylene - Germination - Gibberellins $\left(\mathrm{GA}_{4+7}\right) \cdot$ Hedge mustard · Mucilage - Real-time PCR - Sisymbrium

\author{
Abbreviations \\ ACC 1-Aminocyclopropane-1-carboxylic acid \\ ABA Abscisic acid \\ ET Ethylene \\ GAs Gibberellins \\ GAox GA-oxidase \\ IESS Inhibitors of ET synthesis and signaling \\ PB Paclobutrazol
}

\section{Introduction}

Seed germination begins the postembryonic development of plants, this in turn determining successful seedling establishment and plant propagation. Therefore, germination is tightly controlled by diverse environmental conditions as well as by the developmental program, in which abscisic acid (ABA) and gibberellins (GAs) are some of the main regulators known (Kucera et al. 2005; Yamaguchi et al. 2007; Rodríguez-Gacio and Matilla 2009). A mature and viable seed that has overcome dormancy is prepared to germinate (Bewley 1997; Carrera et al. 2008). Triggered by gradual water uptake, germination occurs once high transcriptomic and proteomic activity are coordinated by the integration of environmental and internal signals, all this resulting in optimal growth (Koornneef et al. 2002; FinchSavage and Leubner-Metzger 2006; Holdsworth et al. 2008). Germination ends with the onset of cell elongation in 
the embryonic axis, for which mitosis is not essential. The process becomes visible when the radicle has protruded through two covering layers (i.e. testa or seed coat and a single endosperm layer in endospermic seeds) at the level of the micropylar region (Bewley 1997; Kucera et al. 2005; Finch-Savage et al. 2007). Two major forces play antagonistic roles in the germination: the growth potential of the radicle and mechanical resistance of the covering layers. In order to complete germination, the growth potential of the radicle must overcome the tissue resistance of the micropylar covering layers. This situation is regulated by hormonal signaling (Kucera et al. 2005; Rodríguez-Gacio and Matilla 2009). Weakening of the micropylar endosperm surrounding the radicle tip appears to be required for radicle protrusion, in which cell-wall hydrolytic enzymes are presumably involved (Finch-Savage and Leubner-Metzger 2006; Nonogaki et al. 2007). By contrast, in some hard-coated seeds the micropylar endosperm presents lower physical constraint against germination than does the lateral endosperm, and hence its structure is predisposed to rupture (Gong et al. 2005). For many endospermic species, seed-coat rupture and endosperm breakage are two sequential steps during germination, e.g., in tobacco (Solanaceae; Leubner-Metzger 2002; Petruzzelli et al. 2003) and in Arabidopsis thaliana, and Lepidium sativum (Brassicaceae; Liu et al. 2005; Müller et al. 2006). ABA inhibits endosperm breakage, but not seed-coat rupture, of after-ripened seeds in these three species. GAs are known to act as ABA antagonists during seed germination by increasing the potential growth of the embryo to overcome the tissue constraints (Kucera et al. 2005) and/or by weakening the endosperm (Bewley 1997; Muiller et al. 2006). GAs promote endosperm rupture in the Brassicaceae plants Arabidopsis, Lepidium, and Sisymbrium officinale (Müller et al. 2006). The GAs-ABA antagonism has been investigated intensively and has become basic to seed biology (Bewley 1997; Finch-Savage and LeubnerMetzger 2006; Nonogaki et al. 2007).

By contrast, precise and confirmed information is lacking in relation to the role of ethylene (ET) in the transition from dormancy to germination and during germination itself (Kucera et al. 2005; Matilla and Matilla-Vázquez 2008). Although maximum ET production is usually detected after radicle emergence has ended, small amounts of gas are also produced in periods preceding protrusion. Moreover, there are seeds that cannot break dormancy by the supply of ET alone, while in other cases this gas is enough (Kucera et al. 2005; Finch-Savage and Leubner-Metzger 2006; Matilla and Matilla-Vázquez 2008). ET synthesis and cell sensitivity are two major factors for germination in Arabidopsis (Siriwitayawan et al. 2003; Holdsworth et al. 2008). Proteomic analysis in Arabidopsis has suggested an essential role of endogenous ET only after radicle protrusion (Gallardo et al. 2002). ET mutants have been generated, and genetic, physiological, and molecular characterization of these mutants is starting to shed light on the involvement of ET in the complex process by which germination is regulated (Matilla and Matilla-Vázquez 2008). Thus, seeds of etr I and ein2 display enhanced primary dormancy, while $\mathrm{ctrl}$ seeds have slightly reduced dormancy compared to the wild type. The etr1-2 mutation in Arabidopsis confers dominant ETinsensitivity and results in a great proportion of mature seeds that exhibit deep primary dormancy (Chiwocha et al. 2005). The complexity of hormonal responses and their functional overlap support the idea of intensive cross-talk between hormone-signaling pathways (Razem et al. 2006; Weis and Ori 2007). Cross-talk between ET and GAs appears to occur in Arabidopsis (de Grauwe et al. 2007, 2008; Feurtado and Kermode 2007), but this situation during seed germination needs to be investigated.

The main purpose of this work was to study the possible role of ET and its interactions with GAs during germination of $S$. officinale L. seeds, as a continuation of our previous work focused in the physiology of the after-ripening (AR) in these seeds (Iglesias-Fernández and Matilla 2009). Taking this into account, we selected several important genes implicated in the metabolism of both hormones. ET is produced in higher plants from methionine (Met) by a well-defined pathway, the last two steps involving (1) the conversion of $S$-adenosyl-Met (SAM) to I-aminocyclopropane-1-carboxylic-acid (ACC), catalyzed by ACC synthase (ACS), a pyridoxal phosphate-dependent enzyme; and (2) the subsequent oxidation of ACC to ET, catalyzed by ACC-oxidase (ACO), an unusual plant dioxygenase that uses ascorbate instead of $\alpha$-ketoglutarate as a reductant (Vandendussche et al. 2006). On the other hand, the last reactions of the GAs biosynthesis pathway are catalyzed by three soluble 2-oxoglutarate dependent dioxygenases, GA200x (gibberellic acid 20-oxidase), GA3ox (gibberellic acid 3-oxidase), and GA20x (gibberellic acid 2-oxidase) (Fagoaga et al, 2007). GA20ox and GA30x catalyze the synthesis of bioactive gibberellins and GA20x catalyzes the conversion of bioactive gibberellins to inactive ones. For all these reasons, we decided to analyze the expression pattern of genes involved in ET synthesis ( $S O A C S 7$ and SoACO2) as well as in GAs synthesis (SoGA200x2 and SoGA3Ox2) and breakdown (SoGA20x2) during the time course of germination in the presence of ET and $\mathrm{GA}_{4+7}$ and their inhibitors (IESS and $\mathrm{PB}$, respectively).

\section{Materials and methods}

Plant material

Siliques of wild hedge mustard (S. officinale L.) were harvested in Galicia (north-western Spain in a place located at 
latitude $+45^{\circ} 52^{\prime} 3 \mathrm{I}^{\prime \prime}$ and longitude $-0 \mathrm{~h} 34 \mathrm{~m} 14 \mathrm{~s}$ at $240 \mathrm{~m}$ above sea level) on $20 \mathrm{July} 2007$, where weather conditions were as follows: $21.3^{\circ} \mathrm{C}$ as average temperature and $61 \%$ of relative humidity. These fruits provided darkbrown and light-brown dry seeds; the dark-brown seeds were selected for our experiments and were cleaned, pooled (mature tresh seeds) and stored for 6 months in a desiccator (30\% humidity) at $21 \pm 0.2^{\circ} \mathrm{C}$ to obtain fully after-ripened seeds.

\section{Light microscopy}

Seeds were fixed in $50 \mathrm{mM}$ sodium phosphate buffer, $\mathrm{pH}$ 6.8 , containing $2 \%(\mathrm{w} / \mathrm{v}) \mathrm{p}$-formaldehyde (Panreac Química, Barcelona, Spain) and $2 \%(\mathrm{v} / \mathrm{v})$ glutaraldehyde (Merck, Darmstadt, Germany) for 2 days at $4^{\circ} \mathrm{C}$. Fixation was followed by an ethanol dilution series as described Gong et al. (2005). Following dehydration, seeds were embedded in LR White Resin (Sigma-Aldrich Química, Madrid, Spain) and cut in 2- $-\mathrm{m}$ sections with a microtome with wet glass knives. Staining was carried out in $0.5 \%$ (w/ v) periodic acid (Merck), Schiff's Reagent (Merck) and 1\% (w/v) Naphthol Blue Black (Sigma-Aldrich Química). A Phase Contrast Attachment "Ph" for Optiphot-2 microscope (Nikon Inc., Melville, NY, USA) was used for bright field microscopy. Images were taken with Coolpix 8400 camera (Nikon).

\section{Germination assays}

Three replicates of 50 seeds were imbibed in $90-\mathrm{mm}$ Petri dishes on two layers of filter paper (Whatman No. 1). In order to accelerate germination, Petri dishes always contained $\mathrm{NO}_{3}{ }^{-}(3 \mathrm{ml}$ of $20 \mathrm{mM} \mathrm{KNO}$, according to Hilhorst and Karssen 1988; Hilhorst 1990; Iglesias-Fernández et al. 2007). Different hormonal treatments were applied: $100 \mu \mathrm{M} \mathrm{GA}_{4+7}, 10 \mu \mathrm{M}$ ethrel (compound that releases ET in solution), $10 \mu \mathrm{M}$ 1-aminocyclopropane-1-carboxylic acid (ACC; ET immediate precursor), $25 \mu \mathrm{M}$ paclobutrazol (PB; well-known GAs biosynthesis inhibitor) or a mixture of synthesis inhibitors [100 $\mathrm{M}$ aminoethoxyvinylglycine (AVG) and $1 \mathrm{mM}$ cobalt chloride $\left.\left(\mathrm{CO}_{2} \mathrm{Cl}\right)\right]$, and signaling [( $10 \mu \mathrm{M}$ silver thiosulphate (STS)] of ET (hereafter IESS). All chemicals were from Sigma-Aldrich Química. Germination experiments were carried out in a growth chamber at $24^{\circ} \mathrm{C}$ with a 16-h photoperiod. Seeds were not surface-sterilized in order to avoid influencing their dormancy status; fungal infections were not detected by light microscope. Seeds were considered germinated when radicle protrusion was visible. The specificity of the ethrel effects in this study was checked as described in Calvo et al. (2004a). Germination tests were performed at least twice using three replicates.

\section{Tetrazolium test and ruthenium red staining}

Intact seeds were incubated in a $1 \%(\mathrm{w} / \mathrm{v})$ aqueous solution of 2,3,5-triphenyltetrazolium chloride (Merck) at $30^{\circ} \mathrm{C}$ in darkness for 2 days. Tetrazolium salts were metabolically reduced to highly colored end products called formazans by $\mathrm{NADH}$-dependent reductases of the endoplasmic reticulum (Berridge et al. 1996). Mucilage was detected in the seed basically as described by Western et al. (2000). In short, the whole seeds were allowed to imbibe on moist filter for between $5 \mathrm{~min}$ and $1 \mathrm{~h}$, before the application of $0.2 \%(\mathrm{w} /$ v) aqueous ruthenium red solution. Seeds were photographed with an Olympus B061 stereomicroscope.

\section{Quantification of ACC}

Tissue frozen at $-80^{\circ} \mathrm{C}(50 \mathrm{mg})$ was homogenized at $4^{\circ} \mathrm{C}$ using a mortar and pestle with sterile distilled water at a $1: 5$ ratio $(\mathrm{FW} / \mathrm{v})$. The homogenate was centrifuged at $8,300 \mathrm{~g}$ (Beckman Avanti J-25 minifuge, rotor JA-18.1 for Eppendorf tubes) for $15 \mathrm{~min}$ at room temperature, and the supernatant was assayed for ACC analysis using Lizada's method (Lizada and Yang 1979).

Total RNA isolation from seeds and cDNA synthesis

For RNA extraction, dark-brown seeds (Iglesias-Fernández et al. 2007) at $0,6,12,18,20,22$, and $26 \mathrm{~h}$ of germination were collected, immediately frozen in liquid $\mathrm{N}_{2}$, and stored at $-80^{\circ} \mathrm{C}$ until used. Three replicates were taken for each point. Seeds were finely ground in liquid $\mathrm{N}_{2}$ using a micro-dismembrator S (Sartorius, Göttingen, Germany) at a shaking frequency of $1,500 \mathrm{~min}^{-1}$ for $2 \mathrm{~min}$. Total RNA was isolated using the phenol extraction/lithium chloride precipitation method (Verwoerd et al. 1989). The integrity and purity of the RNA was checked both electrophoretically and by the $260 /$ $280 \mathrm{~nm}$ absorbance ratio. Total RNA samples were digested with DNase (DNase I recombinant, RNase-Free, Roche Diagnostics, Mannheim, Germany) following the manufacturer's directions. The RNA concentration was estimated by $A_{260}$ measurement, and the samples were stored at $-80^{\circ} \mathrm{C}$. The reagents used in this protocol were supplied by Sigma-Aldrich Química, SA The cDNA was synthesized from $1 \mu \mathrm{g}$ of total RNA using the First-Strand Synthesis kit for RT-PCR (Roche Diagnostics) using oligo-p (dT) as a primer, following manufacturer's directions. Samples were stored at $-20 \mathrm{C}$.

\section{Real-time quantitative PCR assays}

Isolation of $S O G A 3 \circ x 2$, SoGA20ox2, SoGA20x6, SoACO2, and $S O A C S 7$ partial-length cDNAs was carried out as described Iglesias-Fennández and Matilla (2009). PCR analysis was performed with the cDNA extracted at different 
times over the germination process, as stated above, as a template. Specific primer design was performed using the sequences obtained for SoGA3ox, SoGA20ox, SoGA2ox, SOACO, and SOACS. The ISS-RNA was used as a control since it was found to be expressed at constant levels throughout the study period (Supplementary Fig. S1). The PCR was performed in an $\mathrm{iCycler}_{\mathrm{iQ}}{ }^{\mathrm{TM}}$ Real-time Detection System (Bio-Rad Laboratories, Hercules, CA, USA). Specific primers used were SoGA3ox2, 5' CTGTGGTTGG CATTAGGTTC 3', 5' GAGAGTTGAGTCGGTATGGG 3'; SoGA200x2, 5' GGTCTTGGTGAAGGATGG $3^{\prime}, 5^{\prime}$ AAG ATCATGGAGCTTCTGG $3^{\prime}$; SoGA2ox6, 5' GTAGAT GGACTTGAGATTTGC $3^{\prime}, 5^{\prime}$ CAGTCACCGACCAATA CG $3^{\prime} ;$ SoACO2, 5' GGTGATAACCAACGGCAAGT 3', $5^{\prime}$ TGTAGAACGAGGCAATGGAC 3'; SOACS7, 5' GGC TTCTATGTTGTCGGA $3^{\prime}, 5^{\prime}$ CGATCCCTGCCTTCTTA $3^{\prime} ; 18 s R N A, 5^{\prime}$ GGCTCGAAGACGATCAGATA $3^{\prime}, 5^{\prime}$ TC ATAAGGTGCCGGCGGAGT $3{ }^{\prime}$. For each $25-\mu$ reaction, $1 \mu \mathrm{l}$ of sample cDNA was mixed with $12.5 \mu \mathrm{l}$ of $\mathrm{IQ}^{\mathrm{TM}}$ SYBR $^{\mathbb{1}}$ Green Supermix (Bio-Rad Laboratories), $0.5 \mu \mathrm{l}$ of forward primer $(12 \mu \mathrm{M}$, final concentration $240 \mathrm{nM}$ ), $0.5 \mu \mathrm{l}$ of reverse primer ( $12 \mu \mathrm{M}$, final concentration $240 \mathrm{nM}$ ), and $10.5 \mu \mathrm{l}$ of sterile water. Samples were subjected to thermalcycling conditions of DNA polymerase activation at $95^{\circ} \mathrm{C}$ for $4 \mathrm{~min}, 40$ cycles of $45 \mathrm{~s}$ at $95^{\circ} \mathrm{C}, 45 \mathrm{~s}$ at $52^{\circ} \mathrm{C}$ (for SOGA20ox, SOGA2Ox) or $55^{\circ} \mathrm{C}$ (for SOGA3Ox, SOACO and SOACS), $45 \mathrm{~s}$ at $72^{\circ} \mathrm{C}$, and $45 \mathrm{~s}$ at $80^{\circ} \mathrm{C}$, a final elongation step of $7 \mathrm{~min}$ at $72^{\circ} \mathrm{C}$ was performed. The melting curve was designed to increase $0.5^{\circ} \mathrm{C}$ every $10 \mathrm{~s}$ from $62^{\circ} \mathrm{C}$ (for SoGA20ox, SoGA2ox) or $65^{\circ} \mathrm{C}$ (for SoGA3Ox, SOACO and $S O A C S$ ). Real-time PCR analysis was performed with two different cDNAs from the same time-point (from two different RNAs), and each was carried out in triplicate. The amplicon was analyzed by electrophoresis and sequenced once for identity confirmation. Quantification was based on analysis of the threshold cycle (Ct) value as described by Ptaffl (2001).

\section{Statistical analysis}

The statistical treatment was based on a variance analysis and averages/means were compared using the least significant difference (LSD) test at $P<0.05$ (Steel and Torrie 1982).

\section{Results}

Germination of $S$. officinale seeds Histological alterations of seed-coat and endosperm during
the imbibition and protrusion

The mature seeds of the Brassicaceae Arabidopsis, Lepidium (Lill et al. 2005; Müller et al. 2006) and S. officinale
(Fig. 1) are endospermic. The tetrazolium test applied to the seeds used in this work showed that $100 \%$ were alive. The seed is surrounded by the seed coat, which contains the outer and inner integuments (Fig. la; general view of $S$. officinale dry seed). The outer integument includes (1) a mucilaginous cell layer enriched in columella that produce abundant mucilage enveloping the seeds within a few minutes after the beginning of imbibition; this myxospermic character was demonstrated with ruthenium red dye (Iglesias-Fernández et al. 2007); and (2) a palisade epidermal cell layer with thickened cell walls rich in pectin. The inner integument is composed of a thin endodermic layer without differences in the cell-wall thickness (Fig. 1b). The endospermic tissue, containing only one cell layer, appears alongside the inner integument. In dry seeds, these endospermic cells have abundant protein bodies and low cell turgor (Fig. 1b). After $4 \mathrm{~h}$ of imbibition (Fig. . c), (1) the number and height of the columella decrease; (2) the endospermic protein bodies begin to degrade; (3) the cell turgor increases in the endospermic micropylar region; and (4) the onset of water uptake triggers cell elongation and greater pressure of the radicle against the surrounding envelopes. At the end of imbibition (18-19 h) the view is (Fig. 1d; general view) as follows: (1) the palisade cell layer corresponding to micropylar zone is destroyed; (2) the endospermic protein bodies in the micropylar and adjacent to zone are emptied; (3) the micropylar endosperm layer is thinner than at $4 \mathrm{~h}$ of imbibition; (4) the protein bodies begin to degrade in the lateral region of radicle; and (5) the seedcoat rupture occurs near the micropylar zone (Figs. 1d, e). Events described above indicate that the micropylar endosperm breaks and the radicle protrudes ( $\mathrm{Fig} .1 \mathrm{e}$ ). Therefore, $S$. officinale constitutes a good system to study the hormonal control of Brassicaceae endosperm rupture during germination.

The effect of ethrel and $\mathrm{GA}_{t_{+}}$pulses in the germination profile

In control ( $20 \mathrm{mM} \mathrm{KNO}_{3}$ ), protrusion began at $19-20 \mathrm{~h}(2-$ $4 \pm 1 \%$ of germination) and increased rapidly until $25-26 \mathrm{~h}$ (100\% germination). In the presence of $100 \mu \mathrm{M} \mathrm{GA}_{4+7}$ or $10 \mu \mathrm{M}$ ethrel, the protrusion became detectable at $15-16 \mathrm{~h}$ (4-5 $\pm 1 \%$ of germination) and $100 \%$ was reached at $23 \mathrm{~h}$. Quantitatively significant differences were not detected between ethrel and $\mathrm{GA}_{4+7}$ treatments (Fig. 2). In the presence of $\mathrm{ACC}$, the germination percentages were similar to those found with ethrel (Table 1). When $\mathrm{GA}_{4+7}$ and ethrel were added together to the imbibition medium, no boosting of the germination percentage with respect to the individual hormone treatments was observed (Table 1). The maximum germination percentage was barely diminished by the ACC-synthase inhibitor AVG (10 or $100 \mu \mathrm{M})$, while the 
Fig. 1 Structure of a mature $S$. officinale L. seed. Bright field microscopy of longitudinal sections of seeds stained with PAS-Naphthol Blue Black. a Whole dry seed, showing the mature and fully differentiated embryo, the endosperm (aleurone layer), and the testa (seed coat). b, $\mathbf{c}$ Structure of micropylar zone enclosing the radicle tip in the dry seed at $4 \mathrm{~h}$ of imbibition,. d General view of a seed at $18-19$ h of germination showing the testa disrupted and empty proteic bodies (arrows). e Radicle protrusion in germinating seed $(22 \mathrm{~h})$ showing the endosperm broken; $C$ cotyledon, $\mathrm{ChE}$ chalazal endosperm, $\mathrm{Col}$ columella, II inner integument, $M E$ micropylar endosperm, $P L$ palisade layer, $R$ radicle, $S A M$ stem apical meristem, $S C$ seed coat. The letter refers to the position of the close-up section. Experiments were carried out using at least 15 seeds. Size bars are given for each panel
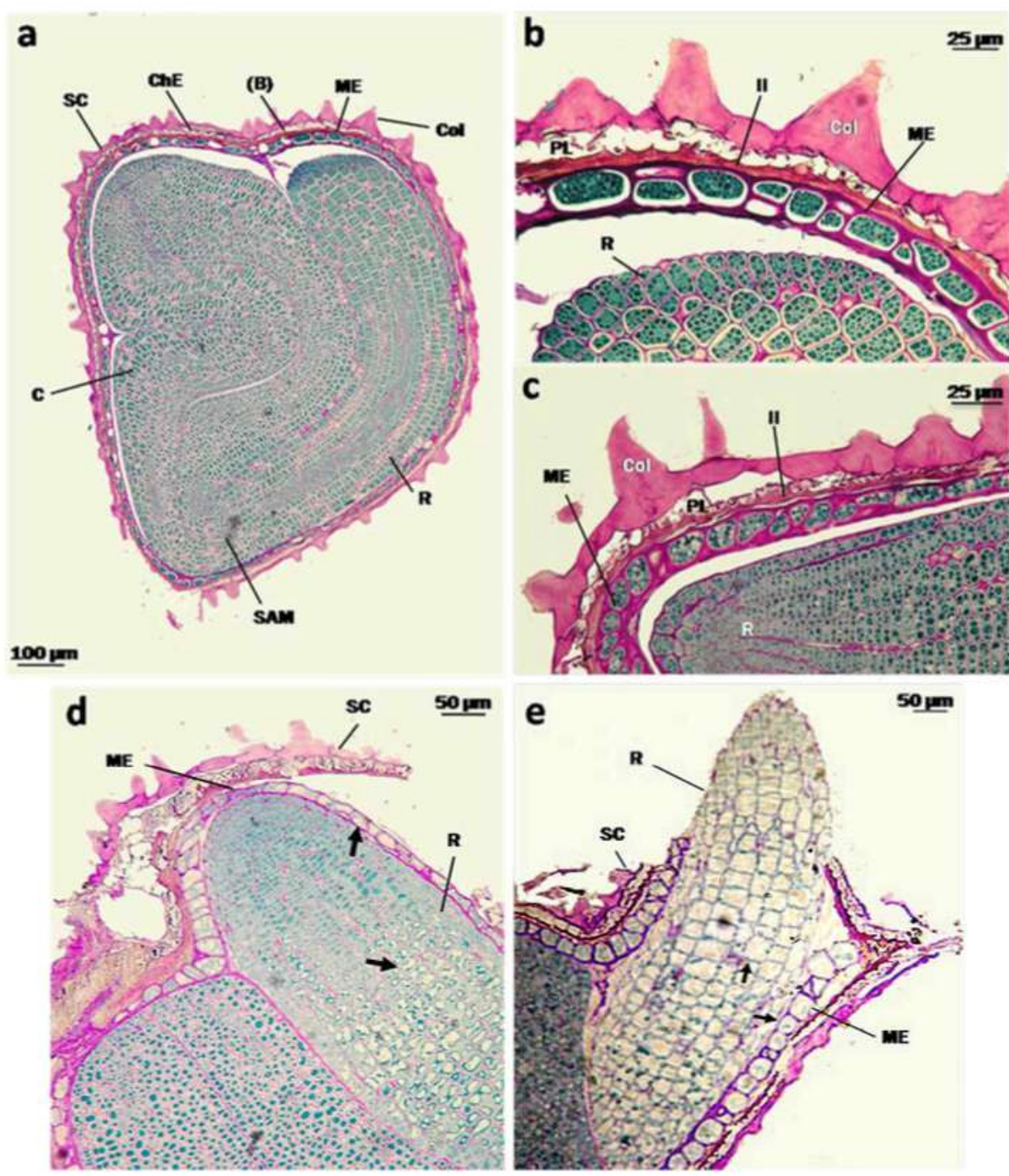

ACC-oxidase inhibitor $\mathrm{Co}^{2+}(100 \mu \mathrm{M})$ slightly decreased it. All these inhibitions were amply overcome by $\mathrm{GA}_{4+7}$ and ethrel, whereas the inhibitor of bioactive GAs synthesis PB strongly prevented it (Table 2 ). We conducted pulse experiments to determine whether the time course of $S$. officinale seed germination was altered by ethrel or $\mathrm{GA}_{4+7}$ added at different times during the imbibition phase; the results referring to the time course may reflect the timing of the synthesis of ET or GAs during imbibition. For this purpose, ethrel or IESS (Fig. 2a-d) and $\mathrm{GA}_{4+7}$ or PB (Fig. 2e-h) were applied at $0,4,8,12$, and $16 \mathrm{~h}$ of imbibition, and the kinetics of induced germination were quantified until $27 \mathrm{~h}$. The germination time course was altered, depending on the time at which the compounds were added. Thus, ethrel and $\mathrm{GA}_{4+7}$ stimulated radicle emergence with respect to control, only when applied early (i.e. 0, 4, and 8 h; Fig. 2a-c, e-g). On the contrary, the hormonal effect was null when ethrel or $\mathrm{GA}_{4+7}$ were added later (i.e. 16 h; Fig. $2 \mathrm{~d}$, h). However, the PB proved to be more efficient germination inhibitor when added early than IESS (Fig. 2a-g), but when they were applied after $16 \mathrm{~h}$ they showed a comparable level of imbibition (Fig. 2a-g).

The effect of ethrel and $\mathrm{GA}_{4+7}$ on ACC content and expression of SOACS7 and SOACO2 genes during seed germination

A slight peak of ACC coinciding with early radicle emergence was detected in control seeds (Fig. 3a). The acceleration of endosperm rupture caused by ethrel and $\mathrm{GA}_{4+7}$ also advanced the appearance of this peak that was quantitatively higher in the presence of ethrel than in that of GAs (Fig. 3b-d). The major levels of ACC observed in the presence of ethrel were perhaps a consequence of autocatalytic production. Moreover, the presence of $\mathrm{GA}_{4+7}$ provoked a sharp decline in ACC after reaching the maximum percentage of endosperm rupture; this was not observed in the presence of ethrel. The ACC content significantly declined with IESS after the imbibition phase, while PB caused the opposite effect (Fig. 3c, e). In the control and all studied 
Fig. 2 Germination time course of Sisymbrium officinale seeds under indicated pulses of $10 \mu \mathrm{M}$ ethrel (black bars), IESS (scratched bars) and control (gray bars) (a-d); and $100 \mu \mathrm{M}$ $\mathrm{GA}_{4+7}$ (black bars); $25 \mu \mathrm{M} \mathrm{PB}$ (scratched bars) and control (gray bars) $(\mathbf{e}-\mathbf{h})$. The specificity of ethrel was from ethylene and not from an acid effect (Gallardo et al. 1991; Calvo et al. 2004a). Data are mean \pm standard error (SE) of five independent experiments

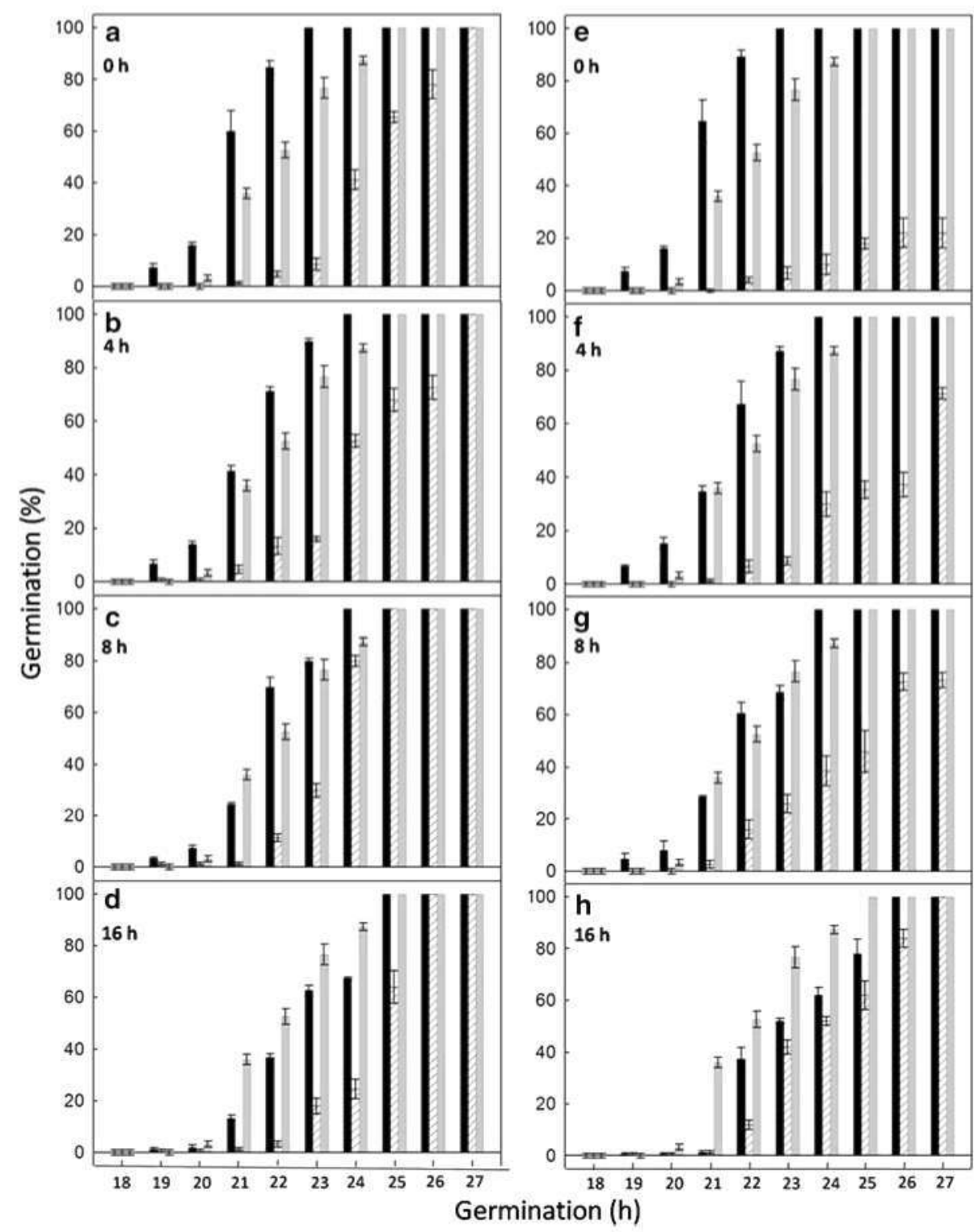

Table 1 Effect of $\mathrm{GA}_{4+7}$ and ethrel on endosperm rupture of after-ripened seeds of $S$. officinale

\begin{tabular}{llllll}
\hline Treatment & \multicolumn{5}{l}{ Endosperm rupture (\%) } \\
\cline { 2 - 6 } & $15 \mathrm{~h}$ & $18 \mathrm{~h}$ & $20 \mathrm{~h}$ & $22 \mathrm{~h}$ & $26 \mathrm{~h}$ \\
\hline Control & - & - & $9 \pm 2 \mathrm{~b}$ & $51 \pm 5 \mathrm{f}$ & 100 \\
$\mathrm{GA}_{4+7}$ & $4 \pm 2 \mathrm{a}$ & $10 \pm 3 \mathrm{~b}$ & $25 \pm 4 \mathrm{~d}$ & $92 \pm 7 \mathrm{~h}$ & 100 \\
Ethrel & - & $8 \pm 2 \mathrm{~b}$ & $24 \pm 3 \mathrm{~d}$ & $89 \pm 6 \mathrm{~h}$ & 100 \\
$\mathrm{ACC}$ & $2 \pm 1 \mathrm{a}$ & $10 \pm 1 \mathrm{~b}$ & $26 \pm 2 \mathrm{~d}$ & $90 \pm 1 \mathrm{~h}$ & 100 \\
$\mathrm{GA}_{4+7}+$ ethrel & - & $5 \pm 1 \mathrm{a}$ & $21 \pm 1 \mathrm{~d}$ & $85 \pm 3 \mathrm{~h}$ & 100 \\
\hline
\end{tabular}

Data are mean values of three independent experiments \pm SD. Significant differences between values as assessed by LSD test $(P>0.05)$ are shown as different letters (Steel and Torrie 1982)

treatments, a notable decrease in ACC content was observed during the onset of imbibition. A possible explanation for this sharp decline is that the ACC was referred to
FW, which augmented markedly in the early stages of imbibition. In other seeds (e.g. chick-pea; Gallardo et al. 1991), a strong amount of ACC and 1-(malonylamino) cyclopropane-1-carboxylic acid (MACC) was lost into the germination medium during the initial stages of soaking. However, the percentage of ACC that can be reabsorbed by the seed is not known.

During imbibition, SoACS7 expression was not detected in control under any of the treatments. However, notable levels of expression were found in the control when endosperm rupture reached $50-100 \%$ (Fig. 3a). This expression was hardly affected by ethrel (Fig. 3b), while it was detected earlier with $\mathrm{GA}_{4+7}$ (Fig. 3d), and IESS caused higher levels of expression at $26 \mathrm{~h}$ of germination (Fig. 3c). The presence of PB completely eliminated SOACS7 expression (Fig. 3e). However, SOACO2 expression, which was barely detected in control seeds during the first $6 \mathrm{~h}$ of 
Table 2 Effect of AVG, $\mathrm{Cl}_{2} \mathrm{Co}, \mathrm{PB}$, and IESS treatments on maximum germination percentage $(26 \mathrm{~h})$ of $S$. offcinale after-ripened seeds

\begin{tabular}{ll}
\hline Control & 100 \\
$\mathrm{AVG}$ & $87 \pm 2$ \\
$\mathrm{AVG}+$ ethrel & 100 \\
$\mathrm{AVG}+\mathrm{GA}_{4+7}$ & $99 \pm 1 \mathrm{c}$ \\
$\mathrm{Cl}_{2} \mathrm{Co}$ & $62 \pm 3 \mathrm{~b}$ \\
$\mathrm{Cl}_{2} \mathrm{Co}+$ ethrel & $98 \pm 2 \mathrm{c}$ \\
$\mathrm{Cl}_{2} \mathrm{Co}+\mathrm{GA}_{4+7}$ & $97 \pm 2 \mathrm{c}$ \\
$\mathrm{PB}$ & $2 \pm 1 \mathrm{a}$ \\
$\mathrm{PB}+$ ethrel & $95 \pm 4 \mathrm{c}$ \\
$\mathrm{PB}+\mathrm{GA}_{4+7}$ & 100 \\
$\mathrm{IESS}$ & $4 \pm 2 \mathrm{a}$ \\
$\mathrm{IESS}+$ ethrel & 100 \\
$\mathrm{IESS}+\mathrm{GA}_{4+7}$ & $99 \pm 1 \mathrm{c}$ \\
\hline
\end{tabular}

Data are mean values of three replicates \pm SE. Significant differences between values as assessed by LSD test $(P>0.05)$ are shown as different letters (Steel and Tortie 1982)

imbibition, rose sharply during the germination process (Fig. 3f). It was stimulated by ethrel and $\mathrm{GA}_{4+7}$ (Fig. 3g, i), and was strongly inhibited by $\mathrm{PB}$ (Fig. $3 \mathrm{j}$ ) but less by IESS (Fig. 3h).

Effect of ethrel and $\mathrm{GA}_{4+7}$ on expression of gibberellin-metabolism genes during seed germination

SoGA200x2 and SoGA30x2 were strongly expressed during the first $6 \mathrm{~h}$ of imbibition (Fig. $4 \mathrm{a}, \mathrm{f}$ ). The level of SoGA200x2 transcripts between 12 and $26 \mathrm{~h}$ was 5-6 times lower than at $6 \mathrm{~h}$, while the SoGA3ox-mRNA levels from 12 to $26 \mathrm{~h}$ were similar and about half the values registered at $6 \mathrm{~h}$ (Fig. $4 \mathrm{a}, \mathrm{f}$ ). The notable and early SoGA200x2 and SoGA3ox expression was markedly inhibited by ethrel (Fig. 4b, g) and $\mathrm{GA}_{4+7}$ (Fig. 4d, i), and was scarcely detected in the presence of ethrel and $\mathrm{GA}_{4+7}$ added together (Iglesias-Fernández and Matilla 2009). Likewise, the level of SoGA200x2 transcript was inhibited by IESS (Fig. 4c) and strongly by PB (Fig. 4e), and this inhibitory effect was stronger for SoGA3ox2, for which the transeript was not detected at $6-18 \mathrm{~h}$ (Fig, $4 \mathrm{~h}, \mathrm{j}$ ). The profiles of SoGA3ox2 expression were very similar in the presence of ethrel and $\mathrm{GA}_{4+7}$ and quantitatively increased with the germination process (Fig. 4g, i).

Contrary to SOGA3OX and SOGA20Ox expression, the SoGA20 $x$ transcript was hardly detectable at $6 \mathrm{~h}$ but peaked around the time of endosperm rupture (i.e. $18-20 \mathrm{~h}$; Fig. 4k). This maximum was strongly inhibited by ethrel and $\mathrm{GA}_{4+7}(\mathrm{Fig}, 4 \mathrm{l}, \mathrm{n})$ as well as by IESS and $\mathrm{PB}$, strongly inhibiting SoGA2ox expression throughout germination (Fig. $4 \mathrm{~m}, 0$ ). Curiously, $\mathrm{GA}_{4+7}$ and ethrel notably raised the levels of SOGA3ox2-mRNA at $6 \mathrm{~h}$ (Fig. $4 \mathrm{l}, \mathrm{n}$ ). A plausible explication for this may be that endogenous $\mathrm{GA}_{4+7}$ and ET induced the synthesis of bio-active GAs through SoGA30x2 (Fig. 5), thereby exceeding the threshold level of GAs needed at $6 \mathrm{~h}$; these GAs induced SoGA20xo expression to degrade them, thereby acquiring again the physiological levels of GAs. By contrast, ethrel and $\mathrm{GA}_{4+7}$ added together inhibited the SoGA20x6 expression to barely detectable levels (Iglesias-Fernández and Matilla 2009).

\section{Discussion}

The $S$. officinale seed is composed of the embryo, surrounded by two covering layers (i.e. seed coat and endosperm), and cotyledons (Fig. 1a, d). The micropylar endosperm surrounding the radicle tip is composed by one cell layer. In $A$, thaliana a monostratified micropylar endosperm also exists (Liu et al. 2005), but one or two layers appear in $L$. sativum (Müller et al. 2006) and a few in L. virginicum (Nguyen et al. 2000). As in Arabidopsis and Lepidinm (Muiller et al. 2006; Bethke et al. 2007; Piskurewicz et al. 2008), the germination of $S$. officinale seeds consists of two sequential phases (i.e. testa rupture followed by endosperm rupture) (Fig. 1e, f). Petruzzelli et al. (2003) showed that two-step-type germination (testa and endosperm rupture) was found in the Cestroidea sub-family of Solanaceae (e.g. Nicotiana and Petunia); but not in the Solanoideae sub-family (e.g. Lycopersicon) (LeubnerMetzger et al. 1998). The role of the testa as a germination constraint has been studied by using Arabidopsis mutants (Koornneef et al. 2002), but the intervention of micropylar endosperm in the seed-coat rupture is still unclear. (1) The secretion of hydrolytic enzymes, for which the substrates are structural components of the cell4 wall (i.e. loosening), and/or (2) the increase in the cellular expansion to cause the physical rupture of the testa, might be possibilities. Thus, the micropylar endosperm in Arabidopsis is considered to be a barrier for radicle protrusion and a determinant factor of coat dormancy (Müller et al. 2006; Bethke et al. 2007). In larger seeds, direct biomechanical measurements of the weakening are possible, showing that $\mathrm{ABA}$ inhibits and GAs promote this process during Lepidium seed germination (Muiller et al. 2006). In tomato and coffee seeds, endosperm weakening appears to be biphasic, and only the second phase leading to endosperm rupture was found to be inhibited by ABA, and it was also demonstrated that ABA inhibits the growth potential of the embryo (Toorop et al. 2000; da Silva et al. 2004). GAs are known to act as ABA antagonists during seed germination by increasing the growth potential of the embryo to overcome the tissue constraints (Kucera et al. 2005) and/or by promoting endosperm weakening (Bewley 1997; Müller et al. 2006). Likewise, GAs can promote the endosperm rupture of the 
Fig. 3 Quantitication of ACC levels and expression of $S O A C S 7$ and $S o A C O 2$, analyzed by realtime qPCR, during germination of $S$. officinale seeds. a-e ACC. levels (squares) and $S O A C S 7$ (circles) expression during germination in presence of different treatments (control, ethrel, IESS, $\mathrm{GA}_{4+7}$, and PB), f-j $\mathrm{S}_{\mathrm{AACO} 2}$ (circles) expression during germination in presence of different treatments (control, ET. IESS, $\mathrm{GA}_{4+7}$ and $\mathrm{PB}$ ) and endosperm rupture rate (triangles). Note that the initial decrease in ACC FW content $(0-6$ h) was related to the fact that FW was used and seed imbibition ended during the first few hours. Error bars represent the standard error of three (ACC quantification and gene expression) and five (germination percentage) independent experiments

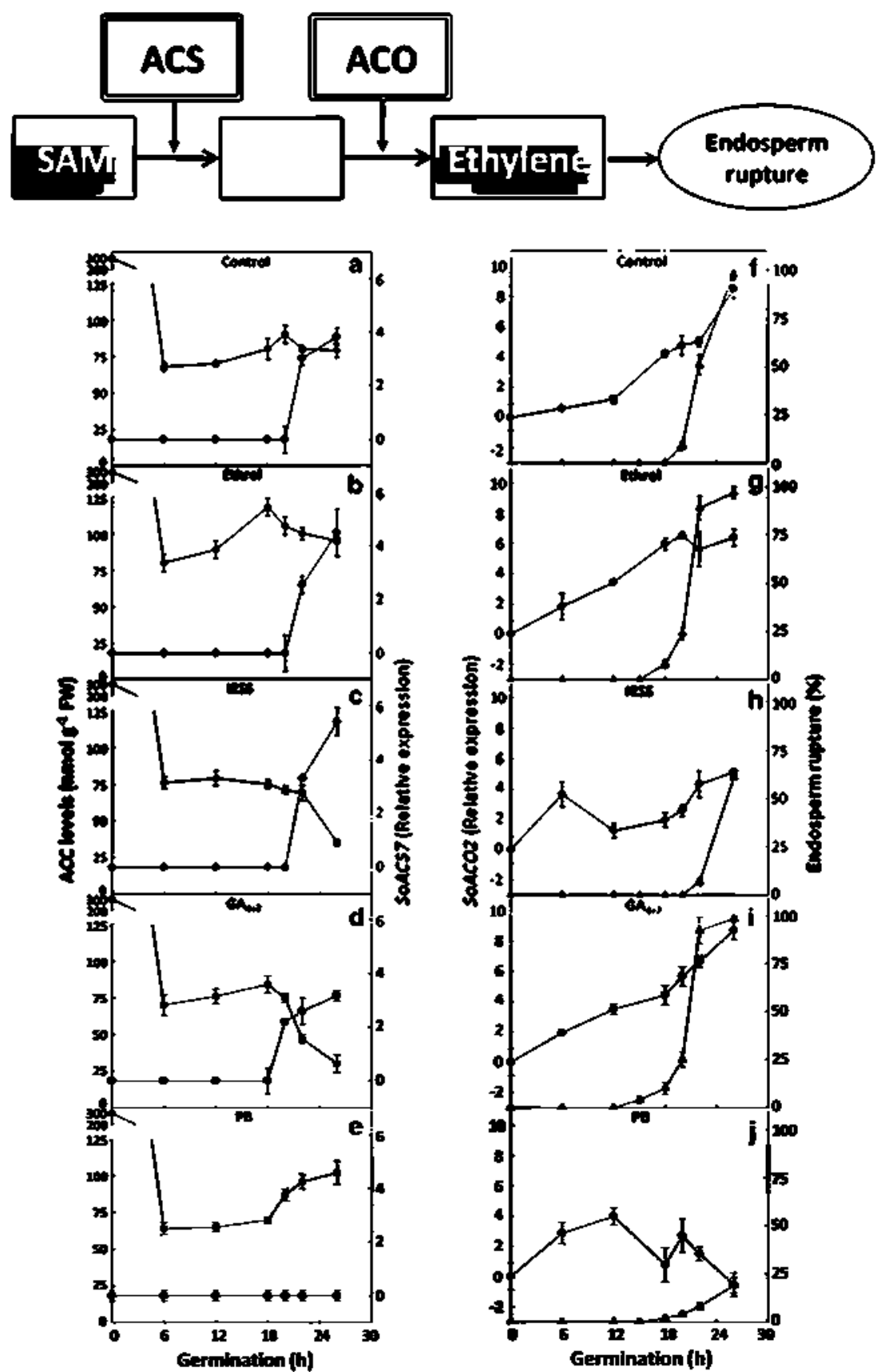

Brassicaceae relatives Arabidopsis, Lepidium, and $S$. officinale (Miiller et al. 2006). Here, we demonstrate that the covering tissues of $\mathrm{S}$. officinale seeds surrounding the radicle apex are structurally altered during the early imbibition. Thus, the palisade layer is disorganized; the cell volume increases in the endosperm layer, and the abundant protein bodies begin to degrade; finally the protein bodies corresponding to sub-apical zone of radicle are also degraded. Similar structural changes were also previously documented (Bewley 1997; Toorop et al. 2000; da Silva et al. 2004; Bethke et al. 2007). Therefore, our results strongly suggest that endosperm weakening occurs in $S$. officinale.
The secretion of mucilage, an extremely hydrophylic pectin-rich polymer, is abundant in imbibed $S$. officinale seeds, completely encircling the seed coat (Fig. 1a-d). The mucilage-producing cells in mixospermous seeds such as $S$. officinale are located in the epidermal tissue of the testa (Western et al. 2004). Because the imbibition process must be tightly regulated in order to start the normal germination process, the mucilage may be involved in slow and controlled water uptake (Penfield et al. 2001). The fruit of $S$. officinale contains two kinds of seeds with respect to the color of their testa (i.e. dark-brown, used here, and lightbrown). The dark-brown seeds have a greater capacity to 
Fig. 4 Expression protile of SOGA20OX2. SOGA3OX2, and SoGA2ox6, analyzed by realtime qPCR, during germination of $S$. officinale seeds. a-e SoGA20ox 2 (circles) expression duting germination in presence of different treatments (control. ethrel, IESS, $\mathrm{GA}_{4+7}$, and $\mathrm{PB}$ ) and endosperm rupture rate (triangles). f-j SoGA3ox 2 (circles) expression duting germination in presence of different treatments (control. ethrel, IESS, $\mathrm{GA}_{4+7}$, and $\mathrm{PB}$ ) and endosperm rupture rate (triangles), $\mathbf{k} \rightarrow \mathbf{0}$ SoGA2x6 (circles) expression during germination in presence of different treatments (control. ethrel, IESS. GA $4+7$, and PB) and endosperm rupture rate (triangles). Error bars represent the standard error of three independent experiments

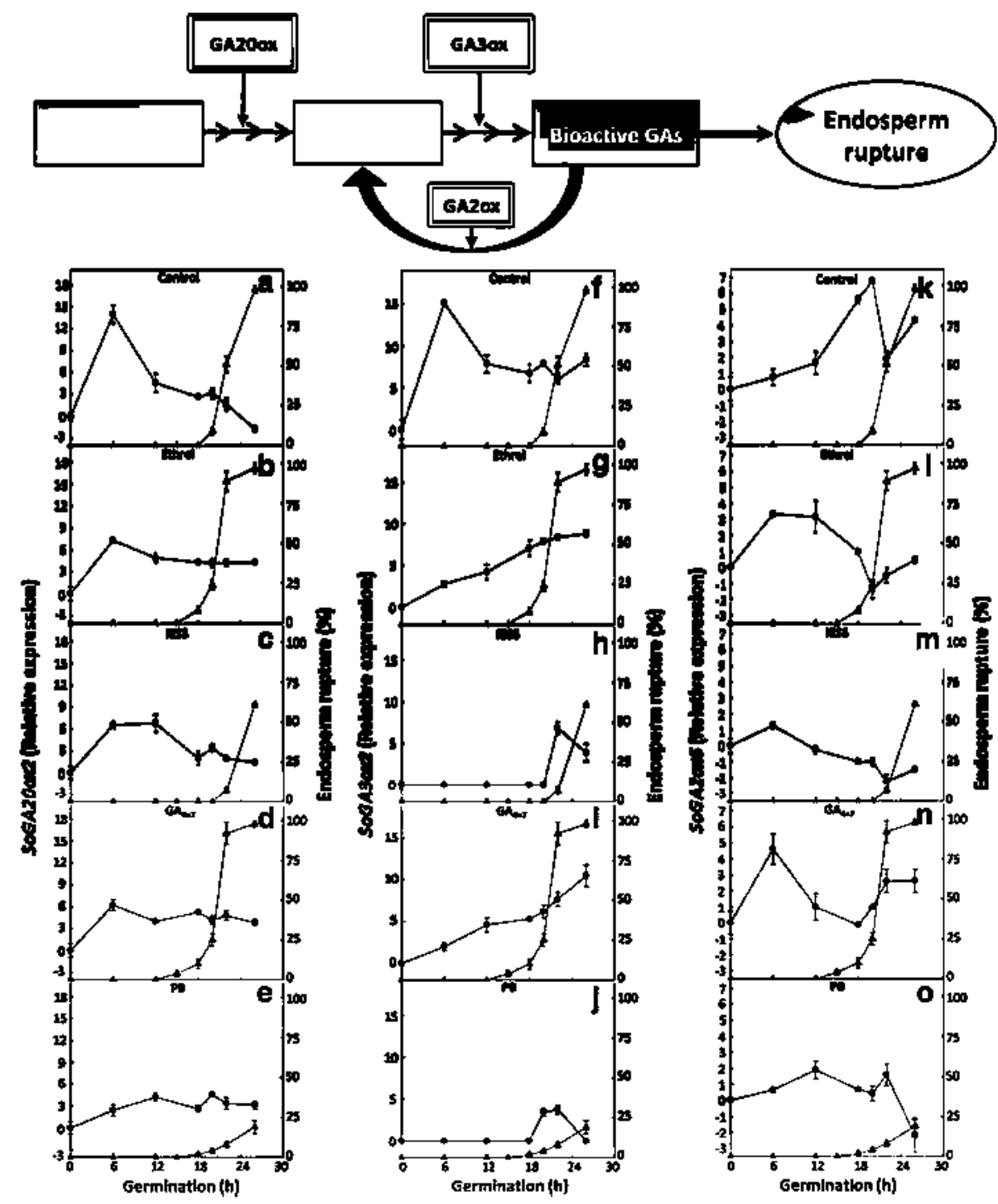

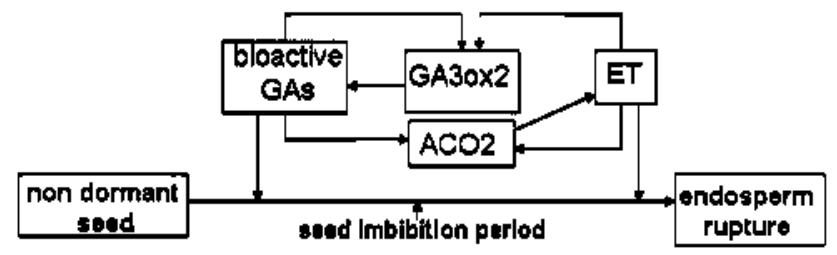

Fig. 5 Model for interaction between ET and GAs during the $S$. offcinale seed germination. According to the interaction. ET and GAs positively act on $S O A C O 2$ and $S O G A 3 O \times 2$. The model was based on Rodriguez-Gacio and Matilla (2009) and the results shown in this work

secrete mucilage, a slower water-uptake rate, and a faster germination rate (Iglesias-Fernández et al. 2007). Therefore, the mucilage might work in $S$. officinale to enhance and control the initial imbibition and therefore the germination process.

The functional overlap between different hormonal responses support the idea of an interaction between the signaling pathways (Brady and McCourt 2003; Chiwocha et al. 2005; De Grauwe et al. 2007, 2008; Holdsworth et al. 2008). The seeds of $S$. officinale are highly sensitive to ET and $\mathrm{GA}_{4+7}$. The germination profiles in its presence were similar and these patterns were not altered by the addition of both hormones together. PB and IESS sharply inhibited the effect induced by $\mathrm{GA}_{4+7}$ and $\mathrm{ET}$, and this inhibition was reversed by $\mathrm{GA}_{4+7}$ and ET, respectively (Iglesias-Fernández and Matilla 2009). Depending on developmental and environmental cues, ET and GAs have additive or synergistic (i.e. one hormone increases the responsiveness to the other) effects (Saibo et al. 2003; Vriezen et al. 2004; de Grauwe et al. 2007). Even though the intervention of GAs in seed germination appears to be beyond any doubt, data on the participation of ET are still scarce (for a review see Matilla and Matilla-Vázquez 2008). In the present work, although similar profiles of germination were induced by ET and $\mathrm{GA}_{4+7}$ added to the beginning of germination, a 
detailed analysis of the germination time-courses shown in Fig. 2 (i.e. experiment of hormonal pulses) suggests a greater need for exogenous $\mathrm{GA}_{4+7}$ than $\mathrm{ET}$. The germination kinetics determined in the presence of $\mathrm{PB}$ was consistent with this observation. Thus, the addition of $P B$ at the beginning of imbibition led to an abrupt slowdown of radicle emergence, and the germination percentage was higher when the inhibitor was applied later. These data aim to a main GAs implication in the early imbibition period, although their synthesis is necessary during the whole germination period. In addition, the reduced germination profiles in the presence of IESS suggest that ET synthesis and signaling are also involved throughout the imbibition period.

To advance the understanding of the participation of ET and GAs during the germination of $S$. officinale seeds, we studied the expression of two genes involved in the ET synthesis (SOACS7 and SOACO2) and three genes involved in GAs synthesis (SoGA200x2, SoGA3Ox2) and degradation (SoGA2OxO). GA biosynthesis takes place during early seed imbibition because germination can be inhibited at that time by GA-biosynthesis inhibitors (Pen and Harberd 2002; Ogawa et al. 2003; Fig. 2e, f of this work). Bioactive-GAs are required for seed germination, as demonstrated by the non-germinating phenotype of the gal-3 Arabidopsis mutant (Koornneef et al. 2002; Ogawa et al. 2003). Likewise, the fact that (1) both SoGA200x2 and SoGA30x2-mRNAs strongly increase in $S$. officinale during early imbibition $(6 \mathrm{~h})$; and (2) the SoGA20x6 expression involved in GAs deactivation is meager at $6 \mathrm{~h}$ in comparison to the rest of the germination period, suggests the involvement of GA synthesis in the preparation for germination of $S$. officinale seeds. Thus, SoGA30x2 is probably more involved than SoGA200x2 in the synthesis of bioactive-GAs during $S$. officinale seed germination, since the levels of SoGA200x2 transcripts are less abundant after $6 \mathrm{~h}$. Given the wide expression of SoGA2ox6 that takes place during the progression of radicle emergence, we can conclude that the level of bioactive-GAs during $S$. officinale seed germination is tightly controlled by the modulation of both their synthesis and catabolism.

The interactions between GAs and ET has been demonstrated to control several pathways of plant growth and development in Arabidopsis (Ogawa et al. 2003; Chiwocha et al. 2005; Weis and Ori 2007; De Grauwe et al. 2008; Dugardeyn et al. 2008). Recently, it was found that hypocotyl elongation induced by ET was dependent on, but not mediated by GAs (Vandenbussche et al. 2007). The Chiwocha's results suggest that ET signaling modulates the metabolism of several plant-hormone pathways in seeds (Chiwocha et al. 2005). In S. officinale seeds, SoACS7 is expressed very late in the germination process, perhaps because the endogenous ACC levels are sufficient to supply
SoACO2, the expression of which was noticeable during protrusion. It is possible that $S O A C S 7$ is not the only member of the SOACS family related to germination; but we failed to isolate others. In this sense, the presence of ethrel or $\mathrm{GA}_{4+7}$, which accelerated radicle emergence in $S$. officinale, positively altered the ACC levels and the SOACO2expression pattern before protrusion. By contrast, in the presence of $\mathrm{PB}$ and IESS, the germination percentage, the ACC content, and the SOACO2 expression were markedly inhibited. The addition of ET triggers a positive reedback that raises the expression of $P S A C O I$ in pea seeds (Petruzzelli et al. 2000). Likewise, the application of $\mathrm{GA}_{3}$ also increased ACC content, ACC-oxidase, FSACOI expression, and ET synthesis in Fagus sylvatica seeds, suggesting some GAs-ET cross-talk (Calvo et al. 2004a). During $\mathrm{GA}_{4}$ treatment of gal-3 seeds, which stimulated the germination, the expression of $A t A C O$ was also increased (Ogawa et al. 2003). Also, the treatment of $g a I-3$ seeds with ET induced its germination (Kucera et al. 2005). When AtACO2 expression was studied, ET was found to be induced in a feed-forward mechanism, the gene serving as a positive control for ET responses (De Paepe et al. 2004). Likewise, the expression of three ACOS genes was altered by ET (De Paepe et al. 2004). Taken together, the results shown in Fig. 3, and the notable levels of ACC existing under all treatments studied here, allow us to conclude that the immediate ET precursor ACC was not a limiting factor and hence the major regulation came via SOACO2 expression, which ethrel and $\mathrm{GA}_{4+7}$ promoted (for hypothesis, see Fig. 5).

Notably, GAs and PB have an opposite effect on the expression of $S O A C S 7$ and SOACO2, but a similar effect on the expression of GAs metabolism genes (SoGA20ox2 and SoGA30X2). Stimulation and inhibition in expression of SOACS7 and SOACO2, caused by GAs and PB (respectively), could reflect the cross-talk GAs-ET. Meanwhile, the inhibition in expression of GAs metabolism genes caused by GAs could be generated by a negative feedback in the metabolism pathway. However, the inhibition provoked by $\mathrm{PB}$ could be a result of the total inhibition of GAs synthesis pathway from ent-kauren oxidase.

Our results indicate an interaction between GAs and ET signaling, since (1) the SoGA30x2 expression was strongly inhibited by PB and IESS, and the hormones studied; (2) ethrel and $\mathrm{GA}_{4+7}$ decreased two times the level of SoGA20002-mRNA during early imbibition and raised that level during germination; (3) PB markedly inhibited the expression of $S \circ G A 200 \times 2$ at $6 \mathrm{~h}$ of imbibition, whereas both $\mathrm{PB}$ and IESS slightly raised the levels of this transcript between 18 and $26 \mathrm{~h}$; (4) SoGA20xo expression was severely inhibited during germination by $\mathrm{PB}$ and IESS, and by $\mathrm{GA}_{4+7}$ and ethrel between 18 and $26 \mathrm{~h}$, but $\mathrm{GA}_{4+7}$ and ethrel stimulated SoGA2ox6 expression at the onset of 
imbibition. Taking all the results together, we suggest that the regulation of the synthesis of bioactive-GAs involved in the germination of $S$. officinale seeds is subjected to a strong control by ET and GAs, and, if the threshold level of necessary GAs to prompt germination is surpassed (e.g. endogenous synthesis or exogenous GAs), a destruction mechanism exists (i.e. SoGA2Ox6) to respond to this unnecessary synthesis. As an alternative proposal, and based on the study of the impact of the etr 1-2 mutation during the germination of $A$. thaliana (Chiwocha et al. 2005), it is possible in $S$. officinale that, (1) PB and IESS cause hormonal compensatory responses, or alternatively, (2) other hormonal pathways are usually regulated, either directly or indirectly, by GAs and ET in a positive or negative way. Germinating beechnut seeds evidenced a regulation crosstalk of $F S G A 200 x I$ expression by GAs and ET (Calvo et al, 2004b). GAs up-regulate the $A C O$ and ET-inducible genes such as HLSl (Lehman et al. 1996) and an ET receptor gene ERSI (Hua and Meyerowitz 1998), suggesting that GAs activate ET biosynthesis and/or response. More recently, an up- and down-regulation by ET of different GAs-metabolism genes was also demonstrated; this finding is also related to ET-GA cross-talk (Dugardeyn et al. 2008).

Acknowledgments This wotk was financially supported by Grant no. CGL2004-01996/BOS from Ministerio de Educación y Ciencia (Dirección General de Investigación) (Spain). R. Iglesias-Fernández is the recipient of a doctoral fellowship from Ministerio de Educación y Ciencia (Spain) at the University of Santiago de Compostela (Spain). We are particularly grateful to Dr. P. Carbonero and Dr. L. LeubnerMetzget for advice regarding figures, discussion. and critical reading of this manuscript. The authors also thank M. C. Gómez-Jiménez for ACC determination and M. C. Rodríguez-Gacio for her comments on a draft of this paper.

\section{References}

Betridge MV, Tan AS, McCoy KD, Wang R (1996) The biochemical and cellular basis of cell proliferation assays that use tetrazolium salts. Biochemistry 4:15-20

Bethke PC, Libourel IGL, Aoyama N. Chung YY. Still DW, Jones RL (2007) The Arabidopsis aleutone layer tesponds to nitric oxide. gibberellin, and abscisic acid and is sufficient and necessary for seed dormancy. Plant Physiol 143:1173-1188

Bewley JD (1997) Seed germination and dormancy. Plant Cell 9:10551066

Brady SM. McCourt P (2003) Hormone cross-talk in seed dormancy. J Plant Growth Regul 22:25-31

Calvo AP. Nicolás C. Lorenzo O. Nicolás G, Rodríguez D (2004a) Evidence for positive regulation by gibberellins and ethylene of $\mathrm{ACC}$ oxidase expression and activity during transition from dormancy to germination in Fagus sylvatica L. seeds. J Plant Growth Regul $23: 44-53$

Calvo AP, Nicolás C. Nicolás G, Rodríguez D (2004b) Evidence for positive cross-talk regulation of a GA20-oxidase ( $F s G A 200 x I$ ) by gibberellins and ethylene during breaking of dormancy in Fagus silvatica seeds. Physiol Plant 120:623-630
Carreta E, Holman T, Medhutst A. Dietrich D. Footitt S. Theodoulou FL. Holdsworth MJ (2008) Seed after-ripening is a discrete developmental pathway associated with specific gene networks in Arabidopsis. Plant J 53:214-224

Chiwocha SDS, Cutler AJ, Abrams SR, Ambrose SJ, Yang J, Ross ARS. Kermode A (2005) The ettl-2 mutation in Arabidopsis thaliana affects the ABA, auxin, cytokinin and gibberellin metabolic pathways during maintenance of seed dormancy, moist-chilling and germination. Plant $\mathrm{J}$ 42:35-48

Da Silva EAA. Toorop PE, van Aelst AC., Hilhorst HWM (2004) Abscisic acid controls embryo growth potential and endosperm cap weakening during coffee (Cofjea arabica cv. Rubi) seed germination. Planta 220:251-261

De Grauwe L, Vtiezen W. Bertrand S, Phillips A, Vidal A. Hedden P, van der Straeten D (2007) Interactions between gibberellin and ethylene signalling pathways in Arabidopsis thaliana. Planta 226:485-498

De Grauwe L، Chaerle L. Dugardeyn J, Decat J, Rieu I. Vtiezen WH, Moritz T, Beemster GTS, Phillips AL. Harberd NP, Hedden P, van der Straeten D (2008) Reduced gibberellin response affects ethylene biosíntesis and responsiveness in the Arabidopsis gat eto 2-I double mutant. New Phytol 177:128-141

De Paepe A, Vuylsteke M, Van Hummelen P, Zabeau M, Van Der Straeten D (2004) Transcriptional profiling by cDNA-AFLP and microatrays analysis reveals novel insights into the early response to ethylene in Arabidopsis. Plant J 39:537-559

Dugardeyn J, Vandenbussche F, Van Der Straeten D (2008) To grow or not grow: what can we learn on ethylene-gibberellin cross-talk by in silico gene expression analysis? J Exp Bot 59:1-16

Fagoaga C, Tadeo FR. Iglesias DJ. Huerta L, Lliso I. Vidal AM. Talon M. Navarro L, Garcia-Martínez JL, Peña L (2007) Engineering of gibberellin levels in citrus by sense and antisense overexpression of a GA20-oxidase gene modifies plant architecture. J Exp Bot 58:1407-1420

Feurtado JA, Kermode AR (2007) A merging of paths: abscisic acid and hormonal cross-talk in the control of seed dotmancy maintenance and alleviation. In: Bradford KJ, Nonogaki H (eds) Seed development. dormancy and germination. Annu Plant Rev $27: 176-223$

Finch-Savage WE, Leubner-Metzger L (2006) Seed dormancy and the control of germination. New Phytol 171:501-523

Finch-Savage WE. Cadman CS, Toorop PE. Lynn JR. Hilhorst HW (2007) Seed dormancy release in Arabidopsis Cvi by dry aftertipening, low temperature, nitrate and light shows common quantitative patterns of gene expression directly by environment specific sensing. Plant J 51:60-78

Gallardo M, Delgado MM, Sánchez-Calle IM, Matilla AJ (1991) Ethylene production and 1-aminocyclopropane-1-carboxylic acid conjugation in thermoinhibited Cicer arietinum L. seeds. Plant Physiol 97:122-127

Gallardo K, Job C, Groot SPC, Puype M, Demol H, Vandekerckhove J, Job D (2002) Importance of methionine biosynthesis for Arabidopsis seed germination and seedling growth. Physiol Plant 116:238-247

Gong X, Bassel G. Wang A. Greewood JS. Bewley JD (2005) The emergence of embryos from hard seeds is related to the structure of the cell walls of the micropylar endosperm, and not to endo- $\beta$ mannanase activity. Ann Bot 96:1165-1173

Hilhorst HWM (1990) Dose-response analysis of factors involved in getmination and secondary dormancy of seeds of Sisymbritun officinale. Plant Physiol 94:1096-1102

Hilhorst HWM. Karssen CM (1988) Dual effect of light on the gibberellins- and nitrate-stimulated seed germination of Sisym. brium officinale and Arabidopsis thaliana. Plant Physiol 86:591-597 
Holdsworth MJ, Bentsink L, Soppe WJJ (2008) Molecular netwotks regulating Arabidopsis seed maturation. after-ripening, dormancy and germination. New Phytol 179:33-54

Hua J, Meyerowitz EM (1998) Ethylene responses and negatively regulated by a receptor gene family in Arabidopsis thaliana. Cell 94:261-271

Iglesias-Fernández R. Matilla AJ (2009) Aftet-ripening alters the gene expression pattern of oxidases involved in the ethylene and gibberellins pathways during the early imbibition of Sisymbrium off. cinale L. seeds. J Exp Bot 60:1645-1661

Iglesias-Feınández R, Matilla AJ, Pulgar I, de la Tone F (2007) Ripe fruits of Sisymbrium officinale L. contain heterogeneous endospermic seeds with different germination rates. Seed Sci Biotech 1:18-24

Koornneef M, Bentsink L, Hilhorst H (2002) Seed dormancy and germination. Curr Opin Plant Biol 5:33-36

Kucera B, Cohn MA, Leubner-Metzger L (2005) Plant hormone interactions during seed dormancy release and germination. Seed Sci Res $15: 281-307$

Lehman A, Black R. Ecker JR (1996) HOOKLESS1, an ethylene response gene, is required for differential cell elongation in the Arabidopsis hypocotyls. Cell 85:183-194

Leubner-Metzger L (2002) Seed after-ripening over-expression of class I $\beta$-1. 3-gluganase confet maternal effects on tobacco testa rupture and dormancy release. Planta 21 5:659-698

Leubnet-Metzger L, Petruzzelli L, Waldvogel R. Vögeli-Lange R، Meins $F$ Jr (1998) Ethylene-responsive element binding protein (EREBP) expression and transcriptional regulation of class I $\beta-1$, 3 glucanase during tobacco seed germination. Plant Mol Biol 38:785-795

Liu P-P. Koizuka N, Homrichhausen TM, Hewitt JR, Martin RC, Nonogaki H (2005) Large-scale screening of Atabidopsis enhancet-trap lines for seed germination-associated genes. Plant J 41:936-944

Lizada MCC., Yang SF (1979) A simple and sensitive assay for 1 -aminocyclopropane-1-carboxylic acid. Ann Biochem 100:140-145

Matilla AJ. Matilla-Vazquez MA (2008) Involvement of ethylene in seed physiology. Plant Sci 175:87-97

Müller K, Tintelnot S, Leubner-Metzger G (2006) Endosperm-limited Brassicaceae seed germination: abscisic acid inhibits enbryo-induced endosperm weakening of Lepiditm sativum (cress) and endosperm rupture of cress and Arabidopsis thaliana. Plant Cell Physiol 47:864-877

Nguyen H, Brown RC, Lemmon BE (2000) The specialized chalazal endosperm in Arabidpsis thaliana and Lepidium virginicum (Brassicaceae). Protoplasma 212:99-110

Nonogaki H, Chen F, Bradford KJ (2007) Mechanisms and genes involved in germination sensu stricto. In: Bradford $\mathrm{K}$, Nonogaki $\mathrm{H}$ (eds) Seed development, dormancy and germination. Annu Plant Rev 27:264-304

Ogawa M, Hanada A, Yamauchi Y, Kuwahara A. Kamiya Y, Yamaguchi S (2003) Gibberellin biosynthesis and response during Arabidopsis seed germination. Plant Cell 15:1591-1604

Pen JR. Harberd NP (2002) The role of GA-mediated signalling in the control of seed germination. Curr Opin Plant Biol 5:376-381

Penfield S. Meissner RC, Shoue DA, Carpita NC. Bevan MW (2001) MYB61 is required for mucilage deposition and extrusion in the Arabidopsis seed coat. Plant Cell 13:2777-2791

Petruzzelli L, Coraggio I, Leubner-Metzger G (2000) Ethylene promotes ethylene biosynthesis during pea seed germination by positive feedback regulation of 1-aminocyclo-propane-1-carboxylic acid oxidase. Planta 211:144-149

Petruzzelli L, Müller K, Hermann K. Leubner-Metzger G (2003) Distinct expression patterns of $\beta-1,3$-glucanases and chitinases during the germination of solanaceous seed. Seed Sci Res 13:139153

Pfaffl MW (2001) A new mathematical model for relative quantification in teal-time RT-PCR. Nucl Acid Res 29:2002-2007

Piskurewicz U, Jikumaru Y, Kinoshita N, Nambara E, Kaniya Y, López-Molina L (2008) The gibberellic acid signaling repressor RGL2 inhibits Arabidopsis seed germination by stimulating abscisic acid synthesis and ABI5 activity. Plant Cell 20:2729-2745

Razem FA, Baron K, Hill RD (2006) Turning on gibberellin and ABA signalling. Curr Opin Plant Biol 9:454-459

Rodríguez-Gacio MC. Matilla AJ (2009) Seed dormancy and ABA signalling: the breakthrough goes on. Plant Signal Behav 4:10351048

Saibo NJM. Vtiezen WH, Beemster G, Van Der Straeten D (2003) Growth and stomatal development of Arabidopsis hypocotyls are controlled by gibberellins and modulated by ethylene and auxins. Plant J 33:989-1000

Siriwitayawan G, Geneve RL, Downie AB (2003) Seed germination of ethylene perception mutants of tomato and Arabidopsis. Seed Sci Res 13:303-314

Steel RG. Tortie JH (1982) Principles and procedures of statistics. Mo Graw-Hill. Tokyo

Toorop PE, van Aelst AC, Hilhorst HWM (2000) The second step of the biphasic endosperm cap weakening that mediates tomato ( $L y$ copersicom esculentum) seed germination is under control of ABA. J Exp Bot 51:1371-1379

Vandenbussche F, Vancompernolle B. Rieu I. Ahmad M. Phillips A, Hedden P. Motitz T, Van Der Straeten D (2007) Ethylene-induced Arabidopsis hypocotyl elongation is dependent on but not mediated by gibberellins. J Exp Bot 58:4269-4281

Vandendussche F, Vtiezen WH, Van Der Straeten D (2006) Ethylene biosynthesis and signaling: a puzzle yet to be completed. In: Hedden P. Thomas SG (eds) Plant hotmone signaling. Blackwell. UK, pe 125-145

Verwoerd TC, Dekker BMM, Koekema A (1989) A small-scale procedure for the rapid isolation of RNAs. Nucl Acids Res $17: 2362-2368$

Vriezen WH, Achard P. Harberd NP, Van Det Straeten D (2004) Ethylene mediated enhancement of apical hook formation in etiolated Arabidopsis thaliana seedlings is gibberellic dependent. Plant J $37: 505-516$

Weis D, Ori N (2007) Mechanism of cross talk between gibberellin and other holmones. Plant Physiol 144:1240-1246

Western TL. Skinner DJ. Haughn GW (2000) Differentiation of mucilage secretory cells of the Arabidopsis seed coat. Plant Physiol $122: 345-355$

Western TL, Diana S, Young DS, Dean GH. Tan WL, Samuels AL. Haughn GW (2004) MUCLLAGE-MODIFIED4 encodes a putative pectin biosynthetic enzyme developmentally regulated by APETALA2, TRANSPARENT TESTA GLABRA1, and GLABRA2 in the Arabidopsis seed coat. Plant Physiol 134:296-306

Yamaguchi S. Kamiya Y. Nambara E (2007) Regulation of ABA and GA levels during seed development and germination in Arabidop. sis. In: Bradford K. Nonogaki H (eds) Seed development, dormancy and germination. Annu Plant Rev 27:224-247 